\title{
How do biological and social kinship play out within families in the U.S.? An evolutionary perspective on perceived parental care and closeness in adolescents ${ }^{1,2}$
}

\author{
Welche Rolle spielt biologische und soziale Elternschaft innerhalb von \\ Familien? Eine evolutionsbiologische Betrachtung der Einschätzung \\ elterlicher Fürsorge und emotionaler Nähe unter Jugendlichen in den USA
}

\begin{abstract}
:
Consistent with inclusive fitness theory, evolutionary biologists predict that individuals care more for their biological than their social children and hence that biological children assess the relationships to their parents better than stepchildren. To test this assumption, we use data from the U.S. National Longitudinal Study of Adolescent Health (Add Health). Unlike many other studies that have been conducted so far, this survey allows us to analyze the consequences of the dynamic between social and biological parent-child relationships within the same families. We use comparisons of sibling pairs and fixed-effects regression to achieve the within-family comparison. Both the descriptive and multivariate regression results confirm that - even after controlling for other relevant influences - biological parenthood matters with regard to children's relationship assessments (perceived parental care and closeness of the parent-child relationship) and in both the
\end{abstract}

\begin{abstract}
Zusammenfassung:
Abgeleitet aus der Theorie der Verwandtenselektion sagen Evolutionsbiologen vorher, dass Individuen gegenüber ihren biologischen Kindern mehr Fürsorge zeigen sollten als gegenüber Kindern, zu denen eine soziale Elternschaft besteht. Entsprechend wird erwartet, dass biologische Kinder die Beziehungen zu ihren Eltern besser einschätzen als Stiefkinder. Zur Überprüfung dieser Hypothese ziehen wir die Daten der U.S. National Longitudinal Study of Adolescent Health (Add Health) heran. Diese Studie erlaubt es, im Gegensatz zu vielen anderen Datenquellen, die Konsequenzen der innerfamilialen Dynamik sozialer und biologischer Eltern-Kind-Beziehungen zu untersuchen. Um diesen Vergleich innerhalb der Familien zu ermöglichen, untersuchen wir Geschwisterdyaden und führen eine fixed-effects-Regression durch. Die Resultate der deskriptiven und der multivariaten Analysen bestätigen, dass der Status biologischer Elternschaft auch dann die Beziehungs-
\end{abstract}

1 This research uses data from Add Health, a program project directed by Kathleen Mullan Harris and designed by J. Richard Udry, Peter S. Bearman, and Kathleen Mullan Harris at the University of North Carolina at Chapel Hill, and funded by grant P01-HD31921 from the Eunice Kennedy Shriver National Institute of Child Health and Human Development, with cooperative funding from 23 other federal agencies and foundations. Special acknowledgment is due to Ronald R. Rindfuss and Barbara Entwisle for assistance in the original design. Information on how to obtain the Add Health data files is available on the Add Health website (http://www.cpc.unc.edu/addhealth). No direct support was received from grant P01-HD31921 for this analysis.

2 We thank Professor Johannes Kopp and Oliver Wisser for helpful comments on earlier drafts of this paper. 
relationships to resident fathers and mothers. In the discussion, we comment on the possible integration of the evolutionary and sociological perspectives and close with some recommendations for future data collection that could allow researchers to analyze the relative impact of biological and social influences on parent-child relationships on a more fine-grained level.

Key words: stepfamilies, siblings, fixed-effects regression, parent-child relations, parental investment, evolutionary psychology, sociobiology einschätzungen der Jugendlichen (wahrgenommene elterliche Fürsorge und emotionale Nähe) vorhersagt, wenn für andere relevante Einflussfaktoren kontrolliert wird - sowohl in Bezug auf die väterliche als auch auf die mütterliche Beziehung. In der Diskussion kommentieren wir das Ergebnis im Hinblick auf eine mögliche Integration evolutionsbiologischer und soziologischer Forschungsperspektiven und schließen mit einigen Empfehlungen für die zukünftige empirische Datenerhebung ab. Eine Umsetzung dieser Empfehlungen könnte es interessierten Forscherinnen und Forschern in Zukunft ermöglichen, die relative Bedeutung biologischer und sozialer Einflüsse auf die Eltern detaillierter zu untersuchen.

Schlagwörter: Stiefelternschaft, Stieffamilien, Geschwister, fixed effects, Eltern-Kind-Beziehungen, elterliches Investment, Evolutionspsychologie, Soziobiologie

\section{Introduction}

A stepfamily arises when a biological parent starts a new relationship, either following the death of the other biological parent or a separation of the two biological parents. Unfortunately, there is a lack of accurate demographic information about stepfamilies in more or less every modern society, but it is estimated that the proportion of stepfamilies, based on all families with minor children in the household, ranges between $10 \%$ and $20 \%$ in different countries (for Germany see: Steinbach 2008; U.S.: Teachman/Tedrow 2008; Canada: Church 1996; Japan: Nozawa 2008; UK: Allan/Hawker/Crow 2001; France: Leridon 1998; Austria: Wilk 2002). Given this substantial number of children living in stepfamilies and the fact that adverse parent-child relationships can lead to a range of negative child outcomes (see Brown 2010; White/Gilbreth 2001), it remains an important question what role the biological status of the parent-child relationship plays. Whereas it has been shown that traditional and non-traditional families alike can provide good environments for child development (Patterson 2001), relative differences between biological and social parent-child relationships may nevertheless appear, particularly where both types coexist in the same families. It is our aim in this paper to focus on these within-family differences, specifically with regard to children's assessments of the relationships to their parents and stepparents. Relationship assessments are based on parental care and emotional closeness reported by the adolescent children. We concentrate on testing the assumption from evolutionary biology that parents invest more in their own biological children than in their stepchildren. From a sociobiological perspective, the birth and rearing of a child are investments that are part of an evolutionary strategy "aimed at" spreading one's own genes.

3 The quotation marks are used to emphasize that we are not speaking of conscious, subjective intentions when speaking of "strategy", "aims", etc. Instead, we refer to psychological mechanisms that 
In previous research, parental investment and the perceived quality of the parent-child relationship have been mostly examined by using small samples and descriptive or bivariate analyses. For the most part, also the problem of unobserved between-family heterogeneity has been ignored. Here, we will improve on previous research by comparing parentchild relationships within the same families, thereby controlling for unobserved betweenfamily heterogeneity, and by including various control variables simultaneously. For this purpose, we will use the genetic pairs data, a subset of the U.S. National Longitudinal Study of Adolescent Health (Add Health). Add Health includes data on different sibship constellations, including full biological, half sibling, and step sibling dyads, thereby facilitating an analysis into the role of social and biological relationship status within families.

In the following section (Section 2), we will first introduce the main concepts of evolutionary theory that are relevant for an explanation of differences in parental behavior towards biological and social children and the resulting assessments of parent-child relationships. Second, we will contrast these with sociological arguments on parent-child relationships and, third, we will summarize results of relevant empirical studies. In Section 3 , we will briefly introduce the data set used in our analysis, the selection of research units, and the operationalization of dependent and independent variables. Section 4 includes the empirical part of the paper. We will first present descriptive results on the absolute differences and relative amount of within-family variance in relationship assessments between sibling dyads that differ in the degree of genetic relatedness. Second, we will proceed with a set of bi- and multivariate, fixed-effects regression models. The results of these models show that under simultaneous control of independent variables like age of the child, gender of the child, and number of siblings, as well as control of unobserved "between-family" heterogeneity, differences between half and step siblings exist that are consistent with predictions from evolutionary theory. In the last section of the paper (Section 5), we sum up and discuss the empirical results of our analyses. Here, a particular emphasis is on assessing the degree of contradiction and complementarity of the sociobiological and sociological perspectives, ultimately leading to a call for an integration of the two theoretical perspectives in order to enable researchers to create more finegrained empirical tests of the relative contribution of biological and social influences on parental behavior.

\section{An integrated perspective on parent-child relations}

\subsection{Evolutionary theory}

From a sociobiological point of view, the birth and rearing of a child is to be seen as an investment in the survival of one's own genes. Trivers (1972: 139) defines investments of parents as ,any investment by the parent in an individual offspring that increases the offspring's chance of survival (and hence reproductive success) at the cost of the parent's

have evolved over time and can therefore, in their effects, be regarded as leading to successful strategies for the proliferation of genes. 
ability to invest in other offspring". In general, a child's fitness increases with the amount of parental investment it receives (Salmon 2005), but every parental investment implies various costs like time, energy, or money. Therefore parents are faced with a trade-off between quantity of children and quality of rearing the individual child.

Whereas this explains why, from an evolutionary perspective, parents adjust their investment in biological children, it does not explain certain forms of kin altruistic behavior, that is, the investment into other genetically close kin at the expense of investing into own biological offspring. In order to explain this type of behavior, it is important to grasp the shift from seeing the individual as the unit of natural selection to the single gene that "seeks" to maximize its fitness (Hamilton 1964a, b). From a gene point of view, the body is merely a carrier, or fitness maximization device, for genes. And the chances for the spread of a gene in the gene pool are increased through reproduction of its own carrier as well as the support of reproduction of other individuals that are likely to share the same genes as ego (i.e., genetically close kin) (Dawkins 2006: 6). It was Hamilton who formalized this trade-off between direct and indirect reproduction) in what is now known as "Hamilton's rule" (Charnov 1977) or as the concept of inclusive fitness. The rule states that altruistic traits are favored by natural selection if the behaviors they give rise to, carry higher benefits than costs, weighted by the genetic relatedness to the person to whom the behavior is directed (see Table 1 for an overview of the genetic relatedness in various biological family relations ${ }^{4}$ ).

Table 1: Genetic relatedness $\mathrm{r}$ between ego and various biological kin

\begin{tabular}{llll}
\hline$r=1$ & $r=.5$ & $r=.25$ & $r=.125$ \\
\hline Identical twin & Full sibling & Half-sibling & First cousin \\
& Parent & Grandparent & \\
& Child & Grandchild & \\
& Aunt/uncle & \\
& Nephew/niece & \\
\hline
\end{tabular}

The preceding paragraphs could falsely give the impression that individuals are conceptualized as rational decision makers with the overarching goal to maximize their genetic utility. But in fact, evolutionary theory predicts only that mechanisms have evolved that maximize inclusive fitness - these mechanisms may operate in a conscious or unconscious way. For sociobiologists, in fact, the particular design of such hypothesized mechanisms has never been of central importance. But with the emergence of evolutionary psychology in the past 25 years, the existence and particular design of such psychological mechanisms has entered into the theoretical and empirical focus of researchers working from an evolutionary perspective (see Barkow/Cosmides/Tooby 1992; Laland/Brown 2002). An advantage of focusing on proximate mechanisms is that it enables researchers to study the conditions under which evolved mechanisms lead to fitness-maximizing (adaptive), fitness-minimizing (nonadaptive), or neutral consequences. The number of specialized psychological mechanisms, or in other words, the actual degree of the modularity of the mind is still much debated

4 For a detailed explanation of how to calculate the genetic relatedness $r$ between relatives, see Dawkins (2006: 91-93). 
among psychologists (Barkow/Tooby/Cosmides 1992; Baumeister 2005; Buss 1995). That is, evolutionary psychology shares with sociology the view of humans as reflexive agents, but unlike many sociologists, evolutionary psychologists do not believe that the mind is a blank slate (Schnettler 2010: 32). Rather, the ability for reflexive and rational action, part of an evolved domain-general architecture, is best understood as biased by other, domainspecific mechanisms (Baumeister 2005).

With regard to parental investment, one would predict that evolution favored the selection of proximate mechanisms that (a) increase the likelihood of having biological offspring, e.g., by means of sexual desire or an emotional desire to have children (cf. Foster 2000; Silk 1990), (b) mechanisms that favor the attendance of adults to care for the needs of infants (see attachment theory: Bowlby 1997), and (c) mechanisms that allow individuals to reliably recognize and to direct investment towards close biological kin (Dubas/Heijkoop/ van Aken 2009; Holmes 2004; Lieberman/Tooby/Cosmides 2007; Tal/Lieberman 2007).

Although the general prediction is that parents are more likely to support their biological children rather than their adoptive, foster, or stepchildren, certain forms of social parenting are nevertheless consistent with an evolutionary framework. This is for example the case, when social parenting is in fact a form of biological parenting by kin genetically more distant than biological parents (e.g., by an aunt or grandmother). Or it is the case when social parenting is a response to other evolved mechanisms like the desire to have and care for children in a situation when having own biological children is not possible $\left(\right.$ adoption $\left.^{5}\right)$. Alternatively, support for a stepchild can be seen as a strategy to win the biological parent of that child as a mating partner for shared biological offspring ${ }^{6}$. In other words, the mere presence of certain forms of social parenthood is not in itself a proof against any relevance of biological factors.

\subsection{Relationship of evolutionary and social science accounts}

Given the preceding discussion, it becomes clear that certain cultural or sociological explanations are not necessarily at odds with evolutionary theory. On the contrary, the human psychological architecture can be seen as a system that has evolved to provide different, flexible behavioral strategies in response to varying constraints in the physical and social environment. These constraints can, for example, result from welfare-state based differences in incentive systems, from the individual economic resources relative to the overall degree of economic development in a country, or from cultural values. We will briefly discuss this with regard to the 'value of children' (VOC) approach. The VOC theory is used to explain cross-cultural differences in fertility and parental investment (Nauck 2007; Nauck/Klaus 2007; Trommsdorff/Nauck 2010). Combining sociological with psychological and economic concepts, it takes into account factors that influence the VOC in different societies

5 In some societies, adoption is more likely than not adoption of genetically related than unrelated children and/or adopted children increase the inclusive reproductive fitness of biological children by means of their contribution to household production (Silk 1980, 1987).

6 Stepparenthood may be a mating rather than a parental investment strategy, e.g., if the stepparent supports the stepchild only to win the biological parent as mating partner for shared biological offspring (Anderson/Kaplan/Lancaster 1999; Anderson et al. 1999; see also Salmon 2005; Silk 1990). 
and the VOC is in turn thought to affect fertility decisions and investments in intergenerational relations. Based on the underlying theory of social production functions (Ormel et al. 1999), three aspects of the VOC are deduced: comfort, social esteem, and affect. Depending on the cultural context and individual resources of the (potential) parents, the desired number of children and the investments they are willing to make may differ substantially. That this approach is not inconsistent with an evolutionary perspective follows from the fact that striving for material comfort and social esteem can themselves be regarded as part of evolved behavioral strategies that contribute to individual self-preservation and reproduction (cf., Gintis 2004). The fewer children are required for gaining material comfort and social esteem, the more parents can enjoy the affect that comes with having and rearing children. But the fact that parents are able to experience this kind of affect is itself an evolved psychological mechanism that ensures that people care for their offspring even when children do not come with any economic or social advantages for parents.

Here we cannot provide a full discussion of the potential for integrating the biological and social science perspectives. But the previous example serves as illustration that they are not necessarily conflicting with each other. In fact, what should be clear from the preceding discussion is that behavior emerges from the interplay of biological and social influences. Therefore, in the empirical analysis of parent-child relationship assessments in this paper, we aim at simultaneously controlling for social and biological factors. Furthermore, by comparing parent-child relationship assessments within families, we control for unobserved differences between families and take the dynamic between biological and social factors as it unfolds within families seriously. Specifically, we expect that mechanisms triggering preferencing of biological offspring only get activated in family situations where both biological and social children are present. Hence, comparing biological parent-child relationships from one family with social parent-child relationships from another family could be misleading.

\subsection{Previous empirical research}

Research comparing biological and social parent-child relations generally supports the assumption that the former are advantaged both with regard to parental investment (e.g., time and money) and subjective relationship assessments (Anderson et al. 1999; Berger et al. 2008; Hamilton/Cheng/Powell 2007; Hofferth/Anderson 2003; Lansford et al. 2001). One difficulty in assessing the relevance of biological versus social ties is to distinguish which differences are due to between-family heterogeneity and which due to parental discrimination within families. A similar argument has been made in the literature on sibling-order effects on children's intellectual development. Here, Rodgers (2001) has shown that at least part of the effect disappears when the admixture of observed and unobserved differences between families is controlled for by shifting the analytical focus from between-family to within-family differences. By focusing on differences between families of different structures (intact ${ }^{7}$, adoptive, step families), many existing studies on stepfa-

7 The term 'intact' is only used to refer to a certain structure of a family, in which both biological parents of a child live together in a partnership. It does not say anything about the state of the family or the quality of the relations of the family members. 
milies are limited in a similar way. By showing that most of the differences in parenting practices of biological fathers and stepfathers can be explained by variation in background characteristics, Berger et al. (2008) provide some preliminary evidence against real parental discrimination based on the biological parent-child status (see also Lansford et al. 2001).

A longitudinal study on the effect of the birth of a new biological child reveals a similar effect for parents' ties to their older step and biological children: Whereas indeed parental attention shifts from older children to the newborn, it does so to the same degree in stepfamilies and families with two biological parents (Stewart 2005). A similar study draws attention to the birth order of the newborn, biological child: Whereas mothers and fathers do report more problems in parenting their stepchildren than their biological children after the birth of a biological child, this effect is only observed if the newborn is the focal parent's first biological child. A study by Manning and Smock (2000) addresses the question of overlapping family households and the impact on investments in children. A central result of this study is that financial support from fathers to children who live with their mothers declines after the birth of a child in the father's new family. The presence of stepchildren in the father's current household does not, however, have a similar effect.

Some studies compare parental investment or subjective relationship assessments between children of the same families. DeLongis and Preece (2002), for instance, show that in families with biological and social children, mothers and fathers report closer relationships to their biological children. However, they do not compare stepfamilies with purely biological families and thereby neglect the possibility that in both types of families similar differences may exist. Henderson and Taylor (1999) provide an extended comparison that not only includes simple and complex stepfamilies but also families with biological ties only. Also, these authors find that mothers and fathers are more involved with their biological than with their stepchildren. What is particularly interesting for our current study is that even in complex stepfamilies, that is, when biological and social children live together in the same family, a difference between social and biological children can be found.

In sum, differences in biological and stepparent-child ties found in between-family analyses persist even in the within-family context. But most of the existing studies are limited because they offer purely descriptive accounts and neglect multiple confounding factors. Our own analysis will be an improvement as compared to previous research by providing a within-family analysis that controls for (unobserved) between-family heterogeneity and at the same time controls for possible confounding within-family differences. The class of variables for which we can estimate effects is limited by the design of our study. We will therefore defer reporting on any possible confounding variables until Section 3.3 where we outline the design of our study and provide a reason for this limitation. Furthermore, only few studies compare differences in mixed step- and biological families with differences in purely biological families. At least in our descriptive analysis, we will fill this gap and compare differences in children's assessment of the relationships to their parents in a variety of biological and social sibling constellations, including twins, full biological siblings, half siblings, and step siblings. From an evolutionary perspective, we expect (a) that differences between siblings in their relationship assessments should be associated with differences between the siblings in the genetic relatedness to the respective parent and (b) that stepchildren assess the relationships to their parents more negatively than biological children if both live in the same family. 


\section{Data and variables}

\subsection{Dataset}

We use data from the U.S. National Longitudinal Study of Adolescent Health (Add Health), a school-based longitudinal study of a nationally representative sample of adolescents. The study has a complex, clustered sampling design, combining sampling of schools and of students within schools. The resulting core sample was amended with special samples to ensure sufficient case numbers for otherwise statistically underrepresented groups (e.g., twins and stepchildren). To obtain information on adolescents' school and family contexts, school administrators, parents, and in some cases, siblings were also interviewed (see Harris et al. n.d.). Here we use data from the first wave, collected in 199495 when respondents were enrolled in grades 7-12.

To facilitate within-family comparisons, we use a special subsample which includes data from adolescents in the core sample and from interviews with at least one sibling of these adolescents living in the same household (Harris et al. 2006). In total, the genetic sample of sibling pairs consists of over 3,000 sibling pairs with different degrees of genetic relatedness: monozygotic twins, dizygotic twins, full siblings, half siblings, and step siblings. A few more types of genetically related siblings (e.g., cousins) or unrelated siblings (e.g., adopted children) were covered as well, but for these groups case numbers were too low (Bearman/Brückner 2002: 1190-1192) to include them in our analysis .

The complex sampling procedure of the core probability sample requires that cases be weighted in order to provide estimates that are representative for adolescents in the U.S. (Chantala/Tabor 1999). However, for those individuals in the genetic sample that are not part of the core probability sample, no such weights are available (Chantala 2001). The sample is thus neither representative of the population nor do weights exist to correct estimates accordingly. But this shortcoming is outweighed by the advantage that the data allow detailed within-family comparisons and to take into account a number of factors that may play a role in mediating the assessment of parent-child relationships.

In the vast majority of families only one, but in about 200 families more than one dyad was interviewed. This unbalanced number of dyads per family would have posed some complications in the analysis. Therefore we retained only one randomly chosen dyad per family. This left us with a data set containing 2,211 twin, full, half, and step sibling pairs.

\subsection{Operationalization of the dependent variable}

Add Health includes data on a variety of parental investment indicators. Here, we concentrate on children's assessments of parental care and closeness: Children were asked how much they thought their resident mother and father cared for them and how close the respective parental relationship was. In this context, "resident" parents are the parents the adolescent lived with at the date of the interview - independent of the biological status of the relationship. For each resident parent, the assessment of the parent-child relationship by adolescents was measured on a scale ranging from one to five, with higher values indicating more positive assessments. For the descriptive analyses in this paper and as de- 
pendent variables in regression models we calculated two separate indices based on the mean of these two items, one for the relationship to the mother (Cronbach's alpha: .64) and one for the the relationship to the father (Cronbach's alpha: .72). For certain purposes, a direct measurement of parental investment may be more appropriate. Here, however, we are interested in the overall degree of parental investment and support. No single investment indicator would reflect this overall degree, given that parents may make up lower investment in one area with higher investment in another area. Justification for the use of subjective indicators comes from both sociological and biological theory. From both perspectives, children are seen, at least initially, as striving to maximize the attention and resources obtained from their parents, even at the cost of reducing investment in their siblings. From an evolutionary point of view, this follows from the genetic difference between siblings ${ }^{8}$ (Salmon 2005; Trivers 1974) and in sociology from the assumption that children are born as rational optimizers ${ }^{9}$ who only learn norms of distributional justice from their parents over time (Handel 1986; Ihinger 1975). We therefore regard the combined subjective assessment of parental care and closeness of the parent-child relationship from the perspective of the child as a good approximation of the overall degree of parental attention and investment the child has received relative to other siblings in the same family. See Table 2 for an overview of the summary statistics of the dependent variables, that is, the relationship assessments to the resident mother and father.

Table 2: Descriptive statistics for the dependent variables (relationship assessment to resident fathers, mothers)

\begin{tabular}{llcrrrr}
\hline & & Mean & SD & Min. & Max. & \% Missing \\
\hline Mothers: & bio & 4,7 &, 5 & 1 & 5 & 0,1 \\
& step & 4,1 &, 9 & 1 & 5 & 19,2 \\
Fathers: & all & 4,7 &, 6 & 1 & 1 & 1,4 \\
& bio & 4,6 &, 7 & 1 & 5 & 0,9 \\
& step & 4,1 & 1,0 & 1 & 5 & 40,7 \\
& all & 4,5 &, 7 & 1 & 5 & 11,1 \\
\hline
\end{tabular}

Data: Add Health Wave I (1994/95), Genetic Pairs Set

As shown in Table 2, the mean relationship assessments with regard to mothers (4.7) and fathers (4.6) are quite high, lying close to the end of a scale ranging from one to five. This is a result that is consistent with the research literature and applies to children at all ages, even in adulthood (see Steinbach 2010; Swartz 2009). In addition, the mean differences of relationship assessments from adolescents to biological and stepparents are shown in Table 2. Even though the mean assessment of relations is also high in stepmothers (4.1) and stepfathers (4.1), we already see here that children assess the relationships to their biological mothers (4.7) and fathers (4.6) clearly better.

8 In this sense, monozygotic twins should, because they share $100 \%$ of their genes, be an exception.

9 Sociology leaves the question why children are born as rational optimizers open. The sociobiological theory of parent-child conflict may be applied to provide such an answer: children are adapted to maximize their inclusive fitness. 


\subsection{Operationalization of the independent variables}

Summary statistics for the independent variables are contained in Table 3. The status of the parent-child relationship (biological or social) was obtained from the responses of children because they display a lower percentage of missing values and cover both resident parents. Whenever possible, information from the parental questionnaire was used to replace missing values in the answers of adolescents. For our purposes, we created a dummy variable for each resident parent (father and mother) which notes whether the respective parent is the biological parent of the focal child or not. As expected, given that child custody decisions after a separation of the parents tend to be made in favor of mothers, more children live with their biological mother (93.0\%) than with their biological father $(74.3 \%)$.

Table 3: $\quad$ Descriptive statistics for the independent variables

\begin{tabular}{|c|c|c|c|c|c|}
\hline \multicolumn{6}{|c|}{ Continuous variables } \\
\hline & Mean & SD & Min. & Max. & $\%$ Missing \\
\hline Years away from mother & ,9 & 3,2 & ,0 & 18,6 & ,1 \\
\hline Years away from father & 2,3 & 4,6 & ,0 & 19,7 & 4,1 \\
\hline Age of child & 16,1 & 1,7 & 11,6 & 21,2 &, 0 \\
\hline Number of biological siblings & 1,7 & 1,3 & ,0 & 12,0 & 0 \\
\hline Number of half siblings & ,3 & ,8 & , 0 & 9,0 & 0 \\
\hline Number of step siblings &, 1 &, 5 &, 0 & 7,0 &, 0 \\
\hline \multicolumn{6}{|c|}{ Binary variables } \\
\hline & & & $\%(0)$ & $\%(1)$ & $\%$ Missing \\
\hline Biological mother (yes = 1) & & & 7,0 & 93,0 & , 0 \\
\hline Biological father (yes = 1) & & & 25,7 & 74,3 & ,0 \\
\hline Parents are married (yes $=1$ ) & & & 12,7 & 87,3 & 12,8 \\
\hline Gender of child (female $=1$ ) & & & 51,1 & 48,9 &, 0 \\
\hline Educ. mother: $>$ high school $($ yes $=1)$ & & & 47,9 & 52,1 & 14,3 \\
\hline Educ. father: > high school (yes = 1) & & & 47,2 & 52,8 & 19,3 \\
\hline
\end{tabular}

Data: Add Health Wave 1 (1994/95), Genetic Pairs Set

Given different needs of children at different ages (Berk 2009), we included age of the child as a control variable (in decimal format). The mean age of the children in our sample is about 16, but it ranges from about 12 to 21 years. Step relations, like friendship or any other social relationship, may be affected by relationship and particularly coresidence duration. Therefore, we use information on the age when the child started to live together with the respective parent. In order to avoid correlation of this variable with the age variable, we recoded it as the number of years the child has not lived together with the resident parent ${ }^{10}$ by the time the interview took place. The average number of years children did not live with their fathers (2.3) is higher than the number for mothers (.9) (see Table 3 ). Excluding the children that always lived with their parents, the adjusted average number of years are $8.7(\mathrm{SD}=4.8)$ for fathers and $7.7(\mathrm{SD}=5.3)$ for mothers.

10 As an alternative we used the percentage of lifetime the child had not lived with the respective parent as an indicator for coresidence. This alternative operationalization did neither yield a meaningful deviation from the model coefficients nor from the model fit in the regression models presented in section 4.3. 
Research shows that both parental and child gender are relevant with regard to parental investment and relationship assessments (e.g., Henderson/Taylor 1999) and gender-homogenous parent-child relations have been found to fare more positively than gender-heterogeneous relationships (Lundberg 2005; Schnettler 2010: 134-135). Therefore, we included gender of the child as a dummy variable. Parental gender is taken into account by calculating separate regression models for fathers and mothers. The literature further points towards the importance of both the degree of institutionalization (Hofferth/Anderson 2003) and the quality of the parental relationship (Skopin/Newman/McKenry 1993): If the stepparent and the biological parent are married and the partnership quality is high, the investment in the partner's child should be higher. Therefore we also included a dummy variable that indicates whether the parents were married at the date of the interview. The vast majority $(87.3 \%)$ of the parents in the sample was married (these could be two biological parents or a biological parent and a stepparent). Good indicators on the quality of the parental relationship, shown in the literature as reducing but not eliminating the investment differences between biological and stepchildren, were unfortunately not available. Furthermore, we included three continuous variables that control for the number of siblings living in the same household, one counting biological, one half-, and one step siblings. With a mean number of 1.7 , most of the children lived with biological siblings, some lived with half siblings (.3), and only a minority with step siblings (.1) (see Table 3). Given that we will look at relative differences within families, the number of siblings is not considered important with regard to the sharing of parental resources. But the size of a particular sibling group in a family may influence family culture in a way that benefits or disadvantages children of the minor group.

But not only the current household in which the child lives matters. For the relationship to a stepparent it may also be relevant what kind of relationship the child has to the biological parent living outside of that household and what other family obligations this biological parent has (see e.g., Manning/Smock 2000; King 2006, 2007, 2009). Although it does not enable us to establish the direction of causality, the introduction of an indicator of the quality of contact between the focal child and the outside biological parent as a control variable may signal a possible interaction between the child's relationship to the stepparent living in the same household with the child's relationship to the biological parent living outside the household. Unfortunately, Add Health does not provide information on the relationship of the child to the outside-living biological parent on the same set of dependent variables. As an alternative, we therefore used a binary variable that indicates whether the child had contact at least weekly to the outside-living parent versus having contact less often or not at all.

The variables introduced so far are all variables that can vary within families. In fixed-effects regression models that we introduce in the next section, only such "familyvariant" variables can be estimated. "Family-invariant" effects can only be estimated when interacted with another, family-variant variable. Parental education was introduced into the analysis in such a way because the literature shows that high-status parents tend to compensate and lower status parents to reinforce endowment differences in children by means of differential parental investment (Hsin 2009; Lareau 2003). In order to test whether parental status acts in a similar way to mediate investment and hence differences 
in parental relationship assessments between biological and social offspring, we introduced a dummy-variable on parents' education to operationalize parental status. This dummy variable indicates whether the parent had a high school degree or less, or a high school degree with additional vocational training or at least college education at the date of the interview. About $50 \%$ of both mothers and fathers in our sample hold more than a high school degree (see Table 3).

\section{Results}

\subsection{Descriptive results}

In Figure 1, we report absolute differences in relationship assessments between siblings by type of sibling dyad and parental gender. In the two bottom panels of the figure, dyads are classified by the biological relatedness of siblings. Here, the absolute differences in relationship assessments increase with the genetic distance between siblings. Not all adjacent type comparisons are statistically significant. But what can clearly be seen is that step siblings have higher absolute differences than full siblings, and full siblings higher ones than monozygotic twins. The case is less clear for dizygotic twins and half siblings. The absolute differences between half siblings are once closer to those of full siblings and once to those of step siblings. This can be explained by a composition effect: Most halfsiblings share the same biological mother but have different fathers; that is, in the bottom right panel, most half-siblings are actually full siblings with regard to their mothers and in the bottom left panel mostly stepchildren with regard to their fathers.

The top two panels of Figure 1 actually provide a cleaner comparison with regard to the relationship status of each sibling vis-à-vis their parents. Here, "bb" indicates dyads in which both siblings are the biological children, "bs" dyads in which one sibling is the biological and one the step child, and "ss" dyads in which both siblings are the stepchildren of the respective parent. Consistent with predictions from evolutionary theory, we see that in both types of step-dyads absolute differences in relationship assessments between siblings are higher than in the biological pairs. Furthermore, absolute differences are higher in mixed, step-biological pairs than in pure stepsibling pairs. But this latter difference is not statistically significant. In an analysis not reported in Figure 1, we could also confirm that the observed differences were in the direction predicted: That is, on average stepchildren in mixed dyads reported lower relationship assessments than biological siblings. 
Fig. 1: Absolute difference in relationship assessments between siblings, by type of sibling dyad, parent-child relationship status, and sex of parent

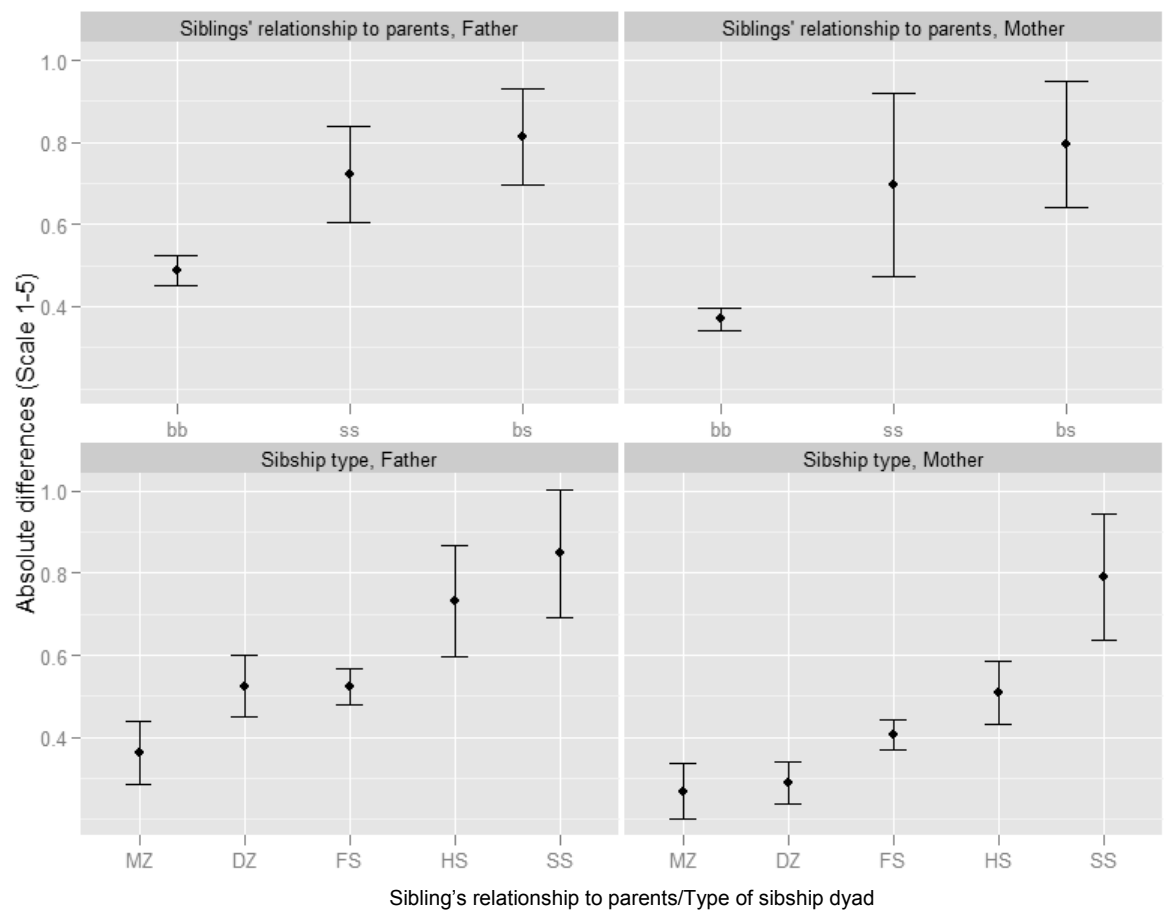

Notes: $\mathrm{bb}=$ focal parent is biological mother $(\mathrm{n}=1876)$ or father $(\mathrm{n}=1192)$ for both siblings, $\mathrm{ss}=$ focal parent is stepmother $(n=32)$ or stepfather $(n=283)$ for both siblings, bs=focal parent is biological mother $(\mathrm{n}=131)$ or father $(\mathrm{n}=222)$ for one sibling and stepparent for the other sibling; $\mathrm{MZ}=$ monozygotic twins $(\mathrm{n}=289), \mathrm{DZ}=$ dizygotic twins $(\mathrm{n}=492), \mathrm{FS}=$ full biological siblings $(\mathrm{n}=1251)$, HS=half siblings $(\mathrm{n}=442)$, $\mathrm{SS}=$ step siblings $(\mathrm{n}=150)$

Data: Add Health, Wave I (1994/95), Genetic Pairs Set

\subsection{Relative degree of between- and within-family variance}

In order to estimate the relative degree of variance explained by within- and betweenfamily differences, we calculated empty, linear random intercept models on the dependent variables with

$$
y_{i f}=\alpha+\gamma_{f}+\varepsilon_{i f}
$$

where $i$ indicates individuals and $f$ families. Here, the family-specific intercept $\gamma_{\mathrm{f}}$ is treated as a random variable. Using the variance components of the model allows to calculate the Intraclass Correlation (ICC). 


$$
I C C=\frac{\sigma_{\gamma}^{2}}{\sigma_{\gamma}^{2}+\sigma_{\varepsilon}^{2}}
$$

It indicates the relative amount of variance of the total variance that is explained by differences between families. And 1-ICC accordingly indicates the variance explained by within-family differences (Table 4). For assessments of the father-child relationship we obtained an ICC of $29.4 \%$ and for mother-child relationships an ICC of $21.3 \%$. That is, in both cases the largest part of the individual variance is explained by differences within families (about $70.6 \%$ and $78.7 \%$ respectively). This result underscores the importance of testing the impact of biological parenthood within rather than between families.

Table 4: Percent between- and within-family variance in random intercept models on children's assessments of the relationships to their resident fathers and mothers, by type of sibship dyad

\begin{tabular}{lcccc}
\hline & $\begin{array}{c}\text { Mother } \\
\text { Between } \\
(\mathbf{I C C})\end{array}$ & $\begin{array}{c}\text { Within } \\
\mathbf{( 1 - I C C )}\end{array}$ & $\begin{array}{c}\text { Father } \\
\text { Between } \\
\text { (ICC) }\end{array}$ & $\begin{array}{c}\text { Within } \\
\mathbf{( 1 - I C C )}\end{array}$ \\
\hline MZ & $40,3 \%$ & $59,7 \%$ & $48,5 \%$ & $51,5 \%$ \\
DZ & $39,6 \%$ & $60,4 \%$ & $35,7 \%$ & $64,3 \%$ \\
FS & $20,8 \%$ & $79,2 \%$ & $25,9 \%$ & $74,1 \%$ \\
HS & $5,8 \%$ & $94,2 \%$ & $32,9 \%$ & $67,1 \%$ \\
SS &, $0 \%$ & $100,0 \%$ &, $5 \%$ & $99,5 \%$ \\
\hline All & $\mathbf{2 1 , 3 \%}$ & $\mathbf{7 8 , 7 \%}$ & $\mathbf{2 9 , 4 \%}$ & $\mathbf{7 0 , 6 \%}$ \\
\hline
\end{tabular}

Notes: $\mathrm{MZ}=$ monozygotic twins, $\mathrm{DZ}=$ dizygotic twins, $\mathrm{FS}=$ full biological siblings, $\mathrm{HS}=$ half siblings, $\mathrm{SS}=$ step siblings

Data: Add Health Wave 1 (1994/95), Genetic Pairs Set

In the next step we calculated random intercept models for sub-samples divided by differences in the genetic relatedness of siblings within families. Roughly, the percentage of within-family variance decreases with increasing genetic similarity of siblings in the same families. These results are affected by both compositional effects and real within-family differences in relationship assessments. The compositional effect is most pronounced for half-siblings (genetic relatedness $=.25$ ): In the vast majority of cases, for half-siblings the mother is the shared biological mother. The father, on the other hand, more often is the stepfather of one sibling and the biological father of the other sibling. In the case of step siblings, the within-family variance reaches (almost) $100 \%$. This means that, on average, differences in relationship assessments between two step siblings in the same family are much larger than differences in the mean relationship assessment between step families.

\subsection{Regression analysis}

In order to facilitate within-family comparisons of child-parent relationship assessments, we performed a number of fixed-effects linear regression models. 


$$
y_{i f}=\alpha+\beta X_{i f}+\gamma Z_{f}+\mu_{f}+\varepsilon_{i f}
$$

Here, $X_{\text {if }}$ includes all covariates that can vary within families and $Z_{\mathrm{f}}$ includes all covariates that differ between families but are fixed within families ("family-invariant"). In the fixed-effects transformation for these models ${ }^{11}$, the $\mathrm{Z}$ term, like the intercept $\alpha$, cancels out. That is, these family-invariant effects are controlled for but cannot be estimated.

In order to find the model that best describes the data, we used a multistage inclusion process. Following guidance from Hosmer and Lemeshow (2000: 95), we started with a series of univariable linear fixed-effects regressions and kept only those variables for inclusion in the multiple regression that were significant on the .25 level $^{12}$. Subsequently, we introduced a number of relevant interaction and quadratic effects into the multiple regression, namely interaction effects between all independent variables and the biological status of the respective parent, an interaction between the status of the focal parent and the second parent, and quadratic effects for all continuous variables. Furthermore, we included an interaction between education of the focal parent and the status of the parent-child relationship. This process yielded one final model for the assessment of the maternal and one for the assessment of the paternal relationship (see "Multiple Regression" in Table 5).

As we can see in Table 5, genetic relatedness between children and both fathers and mothers has a strong and statistically significant effect on relationship assessments: In the bivariate regressions, having a biological parent increases the respective relationship assessment to either the father or the mother by about .6 points. This corresponds to a $15 \%$ change, based on the maximally possible change on the respective scale ranging from 1 to 5. Given that the mean relationship assessments are 4.7 and 4.6 points for maternal and paternal relationships respectively, the actual impact appears even higher. In the bivariate models for relationship assessments to the mother and the father, the effect of the second parent's biological relationship status is diametrical to the focal parent's effect. This is due to confounding of the parental status variables and disappears in the multiple regression.

Other variables that turn out to be relevant in the bi- and multivariate regression models are the number of years away from the respective parent, child age, and child gender: Each year the child did not live together with the focal parent reduces the assessment of the relationship to the respective parent by about .06 and .05 points for mothers and fathers respectively. In the bivariate models for the relationship assessment to the father, not only the years away from the father, but also the years away from the mother matter $(\beta=.03)$. Yet, this effect disappears in the multivariate regression. Furthermore, after controlling for other variables, the effect of years not lived with the respective focal parent remains statistically significant but is reduced in effect size.

11 For details on the procedure see Allison (2005). We used the plm package for the statistical program R to calculate the fixed-effects models (see Croissant/Millo 2008 for details on the implementation in R).

12 For this purpose, in Table 5 variables that are not significant on the .05 but on the .25 level are marked with a \# sign. This has no further relevance for the interpretation of coefficients. 
Table 5: $\quad$ Fixed effects regression on children's assessments of their relationships to their resident fathers and mothers (coefficients and standard errors)

\begin{tabular}{|c|c|c|c|c|}
\hline & \multicolumn{2}{|c|}{ Bivariate Models } & \multicolumn{2}{|c|}{ Multiple Regression } \\
\hline & Mother & Father & Mother & Father \\
\hline Biological mother &, $61^{*}$ &,$- 46^{*}$ &, $29^{*}$ &,- 04 \\
\hline$($ yes $=1, n o=0)$ & $(, 07)$ & $(, 09)$ & $(, 13)$ & $(, 15)$ \\
\hline Biological father &,$- 25^{\star}$ &, $60^{*}$ &,- 02 &, $48^{*}$ \\
\hline$($ yes $=1$, no $=0)$ & $(, 05)$ & $(, 06)$ & $(, 07)$ & $(, 09)$ \\
\hline Years away from mother &,$- 06^{*}$ &, $03^{*}$ &,$- 04^{*}$ &, 00 \\
\hline (Range: 0 - 18.6 years) & $(, 01)$ & $(, 01)$ & $(, 01)$ & , (01) \\
\hline Years away from father &, 01 &,$- 05^{*}$ & &,$- 02^{*}$ \\
\hline (Range: 0 - 19,7 years) & $(, 01)$ & $(, 01)$ & & $(, 01)$ \\
\hline Resident parents & ,10 &,- 50 & & \\
\hline$($ married $=1$, unmarried $=0)$ & $(, 32)$ & $(, 60)$ & & \\
\hline Age in years &,$- 03^{*}$ &,$- 05^{*}$ &,$- 02^{*}$ &,$- 03^{*}$ \\
\hline (Range: 11.6-21.3) & $(, 01)$ & $(, 01)$ & $(, 01)$ & $(, 01)$ \\
\hline Child gender &,$- 09^{*}$ &,$- 19^{*}$ &,$- 09^{*}$ &,$- 17^{*}$ \\
\hline$($ female $=1$, male $=0)$ & $(, 03)$ & $(, 04)$ & $(, 03)$ & $(, 04)$ \\
\hline \# of biological siblings &, $06^{*}$ &, 04 &, 02 & \\
\hline (Range: 0-12) & $(, 02)$ & $(, 04)$ & $(, 04)$ & \\
\hline \# of half siblings &,- 02 &,$- 08 \#$ & ,13\# &,$- 17 \#$ \\
\hline (Range: 0-9) & $(, 03)$ & $(, 05)$ & $(, 08)$ & $(, 10)$ \\
\hline \# of step siblings &,$- 13^{*}$ &,- 04 &,- 02 & \\
\hline (Range 0-7) & $(, 05)$ & $(, 06)$ & $(, 06)$ & \\
\hline \# of half siblings &,$- 18^{*}$ & &,$- 15^{*}$ & \\
\hline$x$ Mother bio $(y / n)$ & $(, 07)$ & & $(, 07)$ & \\
\hline \multirow[t]{2}{*}{$(\# \text { of half siblings })^{2}$} & & & &, 06 \\
\hline & & & & $(, 02)$ \\
\hline \multirow[t]{4}{*}{ Model Statistics } & & $\mathrm{R}^{2}$ & ,07 &, 09 \\
\hline & & & 1735 & 1572 \\
\hline & & & 3298 & 2966 \\
\hline & & & 13,81 & 16,66 \\
\hline
\end{tabular}

Notes: significance levels: $*<.05$, \#<.25; for the models including interaction or quadratic effects in the columns on bivariate (and trivariate) models, the main effects are omitted from the table.

Data: Add Health, Wave I (1994/95), Genetic Pairs Set

The age of the child is also associated with relationship assessments: With each year the age is increased, the relationship assessment is reduced by about .03 and .05 points for the relationships to the mother and father respectively. A possible explanation may be that children increasingly strive for autonomy from their parents or that parents reduce their investment with increasing age of the child, especially if younger siblings with higher age-specific needs live in the household. In the multivariate regressions, the size of the age effect is reduced as well, but it remains statistically significant.

Regarding gender of the child, the literature suggests more positive relationship assessments in gender-homogenous parent-child constellations as opposed to genderheterogeneous ones (Lundberg 2005; Schnettler 2010: 134-135). Whereas this is indeed what we find in relative terms, in absolute terms daughters' relationship assessments are 
lower than those of sons for relationships to mothers and fathers: In the multiple regression, we see that being a daughter reduces the relationship assessment to mothers by about .09 points and to fathers by .17 points.

With regard to mothers, the number of biological $(\beta=.06)$ and stepchildren $(\beta=-.13)$ plays a role in the bivariate regression only. But once other variables are controlled for, the number of half siblings is associated with relationship assessments - though only in the model for the mother. The results of the multiple regression show that each additional half sibling increases the relationship assessment of the focal child if the mother is the focal child's stepmother. Given the negative interaction effect between biological motherchild status and number of half siblings $(\beta=-.15)$, this effect is reversed in case of a biological mother: Here, each additional half sibling reduces the relationship assessment. Given that we do not know details about the other half siblings in the household that were not interviewed (e.g., which parent is the shared biological parent), we can only speculate about the possible reason for this effect. The slightly declining relationship assessment with increasing number of half siblings for children and their biological mother is less surprising: This effect may be a sign that the more children the mother has with the stepfather, the more attention and time goes into the other part of the family - and hence the relationship to the focal child suffers. More difficult to explain is the correlation between the number of half siblings and the relationship assessment between children and their stepmother. Maybe the more children a mother has from her previous relationship, the more she needs to signal that the current family is important to her (either as part of a mating strategy or just as an investment into the stability of the current relationship).

No additional interaction (or quadratic) effects appeared relevant in the analysis - not even the interaction between education and parent-child relationship status. Coming back to the effect of the biological status of the parent-child relationship, we can sum up that even though the effects of biological father- and motherhood are reduced in effect size once all relevant control variables are introduced, biological parenthood continues to be a strong influence on relationship assessments. With coefficients of about .29 and .48 for the biological status of mothers and fathers respectively, the relationship assessment for the respective focal parent differs by about $9-12 \%$ between social and biological siblings. Given a much higher percentage of missing values in relationship assessment among steprather than biological children (see Table 2), the real impact of biological parenthood may even be higher. We have seen in the last section that there is considerable variance within families, but the summary statistics $\left(\mathrm{R}^{2}\right)$ reveal that the current models only explain about $7 \%$ of the variance for mothers and about $9 \%$ of the variance for fathers. We need to develop further hypotheses on possible within-family criteria that may affect parental investment and relationship assessments. In the following discussion of the results, we will make a few remarks on the challenges for future data collection efforts.

\section{Discussion}

Starting point of this paper was the assumption that from an evolutionary perspective, parental care should differ between biological and social children in a way that disadvantages the latter, and that this difference should be mostly visible in families in which bio- 
logical and social parent-child relations coexist. We improved previous research in a number of ways: (1) Descriptively we were able to show that differences in relationship assessments roughly increase with differences in the genetic similarity between siblings, (2) we used fixed-effects regression to control for (unobserved) heterogeneity while estimating the effect of biological parenthood based on within-family differences, (3) and we included relevant family-variant controls in the fixed-effects regression. The conclusion of the analysis is that biological parenthood matters: In all respects stepchildren do provide lower assessments of the relationships to their parents than biological children do.

Even though this result is consistent with predictions from evolutionary theory, we want to emphasize that our results do not necessarily contradict sociological theories. If we go back to the descriptive results reported in Figure 1, we can provide a number of alternative sociological explanations without needing to resort to any genetic differences. Monozygotic twins, we could argue, are more similar than dizygotic twins and full siblings. Therefore, parents find fewer differences to discriminate between their children based on, for example, resemblance to self or preferences for certain types of child personalities or endowments (either in an attempt to compensate for or to reinforce differences, see Hsin 2009). Furthermore, whereas dizygotic twins have the same date of birth, full siblings have an age difference. Therefore changing needs over the life course of children may contribute to differences in parental investment and hence relationship assessments for full siblings. Also, parents are influenced by social norms. Breaches of a norm of equal treatment are discovered more easily the more similar children are. But with increasing genetic distance between siblings, overall differences in parental treatment may be concealed by the complex interplay of parental investment and attention in a large variety of different life domains. In stepfamilies (but not only in stepfamilies), the interplay becomes even more complex because the interests of multiple family members, both within and outside of the own household, are intertwined (for this complex interdependence, cf. King 2006, 2007, 2009; MacDonald/DeMaris 2002; White/Gilbreth 2001).

Again, whereas these statements are indeed alternative explanations, they are not inconsistent with a biological perspective. In fact, the very mechanisms that sociologists draw on may be related to the mechanisms that are assumed to have evolved to increase inclusive fitness. The question of how biological and social factors co-influence parental behavior can only be decided on a more fine-grained level. That is, to provide a real test of the importance of genetic ties in family relationships and not to rely on average measures (like those presented in Table $1^{13}$ ), we need to be able to measure the genetic closeness between specific family members in a more detailed way. The increasing inclusion of biomarkers in surveys is therefore a good step in the right direction (cf. Finch/Vaupel/Kinsella 2001), but it cannot replace an investigation into possible kinship detection mechanisms and the inputs they rely on (cf. Dubas/Heijkoop/van Aken 2009; Holmes 2004; Tal/Lieberman 2007): Even if we are able to measure genetic relatedness on a very detailed level, research on kinship detection may uncover that kin detection predomi-

13 Whereas the genetic relatedness of children to their biological parents is always $50 \%$, the phenotype, that is, the physiological or psychological expression of genes, may be skewed towards one parent, due to different patterns of dominant and recessive genes. Furthermore, children are genetically related to their biological siblings by $50 \%$ on average. In specific cases, resemblance can deviate from this average figure (Dawkins 2006: 91). 
nantly works, for instance, through facial resemblance or olfactory cues. In that case, the challenge would be to implement reliable measures of resemblance of facial or olfactory cues in surveys ${ }^{14}$.

These are but a few examples of challenges in measuring possible biological influences on parental behavior. Furthermore, we need to improve surveys in ways that better capture the full interdependence of kinship relations. This means that to the degree that families' lives are increasingly lived beyond the individual household, survey research needs to reconstruct this complex network structure as best as possible. With regard to biological and step relations this means that a real test of the relative importance of biological and social parenthood requires taking into account the force of biological and social ties within and outside the own household. After all, within-household ties are dependent on ties outside the household (see King 2006, 2007, 2009). Whereas the relationship frequency to the outside-living biological parent did not play a role in our analysis the respective variable did not meet the statistical inclusion criteria for the multivariate regression analysis - a better and more complete measurement of this interdependence of persons living in multiple households may lead to a different conclusion.

For a full consideration of the integrative potential of biological and social explanations with regard to parent-child relationships and to facilitate cross-cultural comparisons, we also need to keep in mind that not all evolved psychological mechanisms immediately have to do with parenting. The extreme longevity that humans reach today is a relatively recent phenomenon. Psychological mechanisms may not be adjusted to this new situation when parents live way beyond the reproductive and rearing phase (to the contrary, see Hawkes 2003 on the grandmother hypothesis). Drives for self-preservation and striving for material comfort, for example, ultimately evolved to improve chances for reproduction but may have reached a certain independence from immediate returns on inclusive fitness under this new longevity regime. A variety of different welfare state arrangements, cultural values, and legal norms can influence parental investment decisions within families in different ways between different countries (regarding value of children (VOC), see Trommsdorff/Nauck 2010). That is, in order to fully understand parental investment also in the cross-cultural comparison, we may need to further investigate behavioral mechanisms like reciprocity and social exchange in family relations and throughout the linked life courses of family members (Brandt et al. 2008; Steinbach 2010: 148-158).

In sum, we were able to show that biological parenthood matters even if we analyze how social and biological ties play out within the same families and control for a number of relevant influences that may also have an impact on parent-child relationships. However, given the current state of data availability, our contribution cannot be a final test for or against biological influences on parental behavior. We have pleaded to abandon the thought that a test between biological and sociological theories is a test of either/or. Instead, we argued that it is a test of how exactly biological and social factors co-influence parental behavior. In the preceding section we have made a few suggestions for necessary improvements in data collection. But data collection itself will not solve this challenge

14 Interesting in this context is also the question to which degree knowledge about genetic relatedness obtained through DNA testing - a possibility our psychological architecture may not be prepared for - can bias influence of emotion-orchestrated psychological kin-detection mechanisms on parental behavior. 
alone. Instead we also need to engage the two theoretical perspectives with each other on a more detailed level than has hitherto been achieved. In order to continue the effort of finding out how the two perspectives can be integrated and tested on a detailed level, scholars need to be creative and courageous and leave old ideological battles behind.

\section{References}

Allan, G., Hawker, S. \& Crow, G. (2001). Family diversity and change in Britain and Western Europe. Journal of Family Issues, 22, pp. 819-837.

Allison, P. D. (2005). Fixed effects regression methods for longitudinal data using SAS. Cary, NC: SAS Institute.

Anderson, K. G., Kaplan, H. \& Lancaster, J. (1999). Paternal care by genetic fathers and stepfathers I: Reports from Albuquerque men. Evolution and Human Behavior, 20, pp. 405-431.

Anderson, K. G., Kaplan, H., Lam, D. \& Lancaster, J. (1999). Paternal care by fathers and stepfathers II: Reports by Xhosa high school students. Evolution and Human Behavior, 20, pp. 433-451.

Barkow, J. H., Cosmides, L. \& Tooby, J. (Eds.) (1992). The adapted mind: Evolutionary psychology and the generation of culture. New York: Oxford University Press.

Baumeister, R. F. (2005). The cultural animal: Human nature, meaning, and social life. Oxford: Oxford University Press.

Bearman, P. S. \& Brückner, H. (2002). Opposite-sex twins and adolescent same-sex attraction. American Journal of Sociology, 107, pp. 1179-1205.

Berger, L. M., Carlson, M. J., Bzostek, S. H. \& Osborne, C. (2008). Parenting practices of resident fathers: The role of marital and biological ties. Journal of Marriage and Family, 70, pp. 625-639.

Berk, L. E. (2009). Child development. Prentice-Hall: Pearson.

Bowlby, J. (1997): Attachment and loss, Vol. 1: Attachment. London: Pimlico.

Brandt, M., Deindl, C., Haberkern, K. \& Szydlik, M. (2008). Reziprozität zwischen erwachsenen Generationen: Familiale Transfers im Lebenslauf. Zeitschrift für Gerontologie und Geriatrie, 41, pp. 374-381.

Brown, S. L. (2010). Marriage and child well-being: Research and policy perspectives. Journal of Marriage and Family, 72, pp. 1059-1077.

Buss, D. M. (1995). Evolutionary psychology: A new paradigm for psychological science. Psychological Inquiry, 6, pp. 1-30.

Buss, D. M. (1999). Evolutionary psychology: The new science of the mind. Boston: Allyn and Bacon.

Chantala, K. (2001). Constructing weights to use in analyzing pairs of individuals from Add Health data. Chapel Hill, N.C.: Carolina Population Center, University of North Carolina at Chapel Hill.

Chantala, K. \& Tabor, J. (1999). Strategies to perform a design-based analysis using the Add Health data. Chapel Hill, N.C.: Carolina Population Center, University of North Carolina at Chapel Hill.

Charnov, E. L. (1977). An elementary treatment of the genetical theory of kin-selection. Journal of Theoretical Biology, 66, pp. 541-550.

Church, E. (1996). Kinship and stepfamilies. In: M. Lynn (Ed.), Voices. Essays on Canadian families. Scarborough, Ont.: Nelson ITP, pp. 81-105.

Croissant, Y. \& Millo, G. (2008). Panel data econometrics in R: The plm package. Journal of Statistical Software, 27, pp. 1-43.

Dawkins, R. (2006). The selfish gene: 30th anniversary edition. Oxford, UK: Oxford University Press ( $3^{\text {rd }}$ edition).

De Graaf, P. M. \& Fokkema, T. (2007). Contacts between divorced and non-divorced parents and their adult children in the Netherlands: An investment perspective. European Sociological Review, 23, pp. 263-277.

DeLongis, A. \& Preece, M. (2002). Emotional and relational consequences of coping in stepfamilies. Marriage and Family Review, 34, pp. 115-138. 
Dubas, J., Heijkoop, M. \& van Aken, M. (2009). A preliminary investigation of parent-progeny olfactory recognition and parental onvestment. Human Nature, 20, pp. 80-92.

Finch, C. E., Vaupel, J. W. \& Kinsella, K. G. (Eds.) (2001). Cells and surveys: Should biological measures be included in social science research? Washington, DC: National Academies Press.

Foster, C. (2000). The limits to low fertility: A biosocial approach. Population and Development Review, 26, pp. 209-234.

Gintis, H. (2004). Towards the unity of the human behavioral sciences. Politics Philosophy Economics, 3 , pp. 37-57.

Hamilton, W. D. (1964a). The genetical evolution of social behaviour. I. Journal of Theoretical Biology, 7, pp. 1-16.

Hamilton, W. D. (1964b): The genetical evolution of social behaviour. II. Journal of Theoretical Biology, 7, pp. 17-52.

Hamilton, L., Cheng, S. \& Powell, B. (2007). Adoptive parents, adaptive parents: Evaluating the importance of biological ties for parental investment. American Sociological Review, 72, pp. 95-116.

Handel, G. (1986). Central issues in the construction of sibling relationships. In: A. S. Skolnick \& J. H. Skolnick (Eds.), Family in transition: Rethinking marriage, sexuality, child rearing, and family organization. Boston: Little, Brown and Company, pp. 384-403.

Harris, K. M., Tucker, C. H., Smolen, A. \& Haberstick, B. C. (2006). The National Longitudinal Study of Adolescent Health (Add Health) twin data. Twin Research and Human Genetics, 9, pp. 988-997.

Harris, K. M. et al. (n.d.). The National Longitudinal Study of Adolescent Health: Research design. http://www.cpc.unc.edu/addhealth/design [Retrieved: 2009-03-10].

Hawkes, K. (2003). Grandmothers and the evolution of human longevity. American Journal of Human Biology, 15: pp. 380-400.

Henderson, S. H. \& Taylor, L. C. (1999). Parent-adolescent relationships in nonstep-, simple step-, and complex stepfamilies. Monographs of the Society for Research in Child Development, 64, pp. 79-100.

Hofferth, S. L. \& Anderson, K. G. (2003). Are all dads equal? Biology versus marriage as a basis for paternal investment. Journal of Marriage and Family, 65, pp. 213-232.

Holmes, W. G. (2004). The early history of Hamiltonian-based research on kin recognition. Annales Zoologici Fennici, 41, pp. 691-711.

Hosmer, D. W. \& Lemeshow, S. (2000). Applied logistic regression. Hoboken, NJ: John Wiley and Sons $\left(2^{\text {nd }}\right.$ edition).

Hsin, A. (2009). Is biology destiny? A sociobiological explanation for divergent destinies. Presented at the 2009 Annual Meeting of the Population Association of America in Detroit.

Ihinger, M. (1975). The referee role and norms of equity: A contribution toward a theory of sibling conflict. Journal of Marriage and the Family, 37, pp. 515-524.

Kalmijn, M. (2008). The effects of separation and divorce on parent-child relationships in ten European Countries. In: Saraceno, C. (Ed.), Families, ageing and social policy. Intergenerational solidarity in European welfare states. Cheltenham, Northampton, MA: Edward Elgar, pp. 170-193.

Kalmijn, M. \& Dykstra, P. A. (2006). Differentials in face-to-face contact between parents and their grown-up children. In: Dykstra, P. A., Kalmijn, M., Knijn, T. C. M., Komter. Liefbroer, A. C. \& Mulder, C. H. (Eds.), Family solidarity in the Netherlands. Amsterdam: Dutch University Press, pp. 63-87.

King, V. (2006). The antecedents and consequences of adolescents' relationships with stepfathers and nonresident fathers. Journal of Marriage and Family, 68, pp. 910-928.

King, V. (2007). When children have two mothers: Relationships with nonresident mothers, stepmothers, and fathers. Journal of Marriage and Family, 69, pp. 1178-1193.

King, V. (2009). Stepfamily formation: Implications for adolescent ties to mothers, nonresident fathers, and stepfathers. Journal of Marriage and Family, 71, pp. 954-968.

Laland, K. N. \& Brown, G. R. (2002). Sense and nonsense: Evolutionary perspectives on human behaviour. Oxford, UK: Oxford University Press.

Lareau, A. (2003). Unequal childhoods. Berkeley and Los Angeles, CA: University of California Press. 
Lansford, J. E., Ceballo, R., Abbey, A. \& Stewart, A. J. (2001). Does family structure matter? A comparison of adoptive, two-parent biological, single-mother, stepfather, and stepmother households. Journal of Marriage and Family, 63, pp. 840-851.

Leridon, H. (1998). Fortsetzungsfamilien in den statistischen Quellen. In: Meulders-Klein, M.-T. \& Théry, I. (Eds.), Fortsetzungsfamilien. Neue familiale Lebensformen in pluridisziplinärer Betrachtung. Konstanz: UVK, pp. 83-110.

Lieberman, D., Tooby, J. \& Cosmides, L. (2007). The architecture of human kin detection. Nature, 445, pp. 727-731.

Lundberg, S. (2005). Sons, daughters, and parental behaviour. Oxford Review of Economic Policy, 21, pp. 340-356.

MacDonald, W. L. \& DeMaris, A. (2002). Stepfather-stepchild relationship quality. The stepfather's demand for conformity and the biological father's involvement. Journal of Family Issues, 23, pp. 121-137.

Manning, W. D. \& Smock, P. J. (2000). "Swapping" families: Serial parenting and economic support for children. Journal of Marriage and the Family, 62, pp. 111-122.

Nauck, B. (2007): Value of children and the framing of fertility: Results from a cross-cultural comparative survey in 10 societies. European Sociological Review, 23, pp. 615-629.

Nauck, B. \& Klaus, D. (2007): The varying value of children. Empirical results from eleven societies in Asia, Africa and Europe. Current Sociology, 55, pp. 487-503.

Nozawa, S. (2008). The social context of emerging stepfamilies in Japan: Stress and support for parents and stepparents. In: Pryor, J. (Ed.), The international handbook of stepfamilies. Policy and practice in legal, research, and clinical environments. Hoboken, NJ: John Wiley \& Sons, pp. 7999.

Ormel, J., Lindenberg, S., Steverink, N. \& Verbrugge, L. M. (1999). Subjective well-being and social production functions. Social Indicators Research, 46, pp. 61-90.

Patterson, C. J. (2001). Nontraditional families and child development. In: Smelser, N. J. \& Baltes, P. (Eds.), The international encyclopedia of the social and behavioral sciences. Oxford: Pergamon, pp. 10699-10702.

Pryor, J. (Ed.) (2008). The international handbook of stepfamilies. Policy and practice in legal, research, and clinical environments. Hoboken, NJ: John Wiley \& Sons.

Rodgers, J. L. (2001). What causes birth order-intelligence patterns? The admixture hypothesis, revived. American Psychologist, 56, pp. 505-510.

Salmon, C. (2005). Parental investment and parent-offspring conflict. In: Buss, D. M. (Ed.), Handbook of evolutionary psychology. Hoboken, NJ: Wiley, pp. 506-527.

Schnettler, S. (2010). Nature + nurture = love? Yale University. Ann Arbor, MI: UMI Dissertation Publishing (Dissertation).

Segerstråle, U. \& Olofsdotter, C. (2000). Defenders of the truth: The battle for science in the sociobiology debate. Oxford: Oxford University Press.

Silk, J. B. (1980). Adoption and kinship in Oceania. American Anthropologist, 82, pp. 799-820.

Silk, J. B. (1987). Adoption among the Inuit. Ethos, 15, pp. 320-330.

Silk, J. B. (1990). Human adoption in evolutionary perspective. Human Nature, 1, pp. 25-52.

Skopin, A. R., Newman, B. M. \& McKenry, P. C. (1993). Influences on the quality of stepfatheradolescent relationships: View of both family members. Journal of Divorce and Remarriage, 19, pp. 181-196.

Steinbach, A. (2008). Stieffamilien in Deutschland. Ergebnisse des ,Generations and Gender Survey' 2005. Zeitschrift für Bevölkerungswissenschaft, 33, pp. 153-180.

Steinbach, A. (2010). Generationenbeziehungen in Stieffamilien. Der Einfluss leiblicher und sozialer Elternschaft auf die Ausgestaltung von Eltern-Kind-Beziehungen im Erwachsenenalter. Wiesbaden: VS Verlag für Sozialwissenschaften.

Stewart, S. D. (2005). How the birth of a child affects involvement with stepchildren. Journal of Marriage and the Family, 67, 461-473.

Swartz, T. T. (2009). Intergenerational family relations in adulthood: Patterns, variations, and implications in the contemporary United States. Annual Review of Sociology, 35, pp. 191-212. 
Tal, I. \& Lieberman, D. (2007). Kin detection and the development of sexual aversions: Toward an integration of theories on family sexual abuse. In: Salmon, C. \& Shackelford, T. K. (Eds.), Family relationships: An evolutionary perspective. New York: Oxford University Press, pp. 205-230.

Teachman, J. \& Tedrow, L. (2008). The demography of stepchildren in the United States. In: Pryor, J. (Ed.), The international handbook of stepfamilies. Policy and practice in legal, research, and clinical environments. Hoboken, NJ: John Wiley \& Sons, pp. 3-29.

Trivers, R. L. (1972). Parental investment and sexual selection. In: Campbell, B. (Ed.), Sexual selection and the decent of man 1871-1971. London: Heinemann, pp. 136-179.

Trivers, R. L. (1974). Parent-offspring conflict. American Zoologist, 14, pp. 249-264.

Trommsdorff, G. \& Nauck, B. (2010). Value of children: A concept for better understanding crosscultural variations in fertility behavior and intergenerational relationships. Journal of Cross-Cultural Psychology, 41, pp. 637-651.

White, L. \& Gilbreth, J. G. (2001). When children have two fathers: Effects of relationships with stepfathers and noncustodial fathers on adolescent outcomes. Journal of Marriage and Family, 63, pp. 155-167.

Wilk, L. (2002). Stieffamilien in Österreich. In: Bien, W., Hartl, A. \& Teubner, M. (Eds.), Stieffamilien in Deutschland. Eltern und Kinder zwischen Normalität und Konflikt. Wiesbaden: Leske + Budrich, pp. 245-284.

Eingereicht am/Submitted on: 19.01.2011

Angenommen am/Accepted on: 07.06.2011

Addresses of the authors/Anschrift des Autors und der Autorin:

Sebastian Schnettler, Ph.D. (Corresponding author/Korrespondenzautor)

Universität Konstanz

FB Geschichte und Soziologie

Institut für Soziologie

Universitätsstraße 1

78457 Konstanz

Germany/Deutschland

E-Mail: sebastian.schnettler@uni-konstanz.de

PD Dr. Anja Steinbach

Technische Universität Chemnitz

Institut für Soziologie

Thüringer Weg 9

09107 Chemnitz

Germany/Deutschland

E-Mail: anja.steinbach@tu-chemnitz.de 